\title{
A global system for mobile communications-based electrical power consumption for a non-contact smart billing system
}

\author{
Ihsan Jabbar hasan', Bushra Mahmoud Waheib², Nahla abdul Jalil salih ${ }^{3}$, \\ Nadhir Ibrahim Abdulkhaleq ${ }^{4}$ \\ ${ }^{1,2,3}$ Department of Electronic, Institute of Medical Technology, Middle Technical University, Iraq \\ ${ }^{4}$ Department of Mobile Computing and Communications Engineering, College of Engineering, University of Information \\ Technology and Communications (UoITC), Iraq
}

\begin{tabular}{l}
\hline \hline Article Info \\
\hline Article history: \\
Received Jan 4, 2021 \\
Revised Apr 22, 2021 \\
Accepted May 11, 2021
\end{tabular}

\section{Keywords:}

Arduino uno

Billing system

GSM module

Non-contact

Power meter

\begin{abstract}
This paper proposes a cheap solution to be a starting point for building smart electrical power billing systems. Electrical power has many challenges issues in Iraq, one of these challenges and the most important is the Billing system. The smart power meter uses an Arduino Uno as the core for controlling the sensed data and transmits it to the electrical power unit for billing services. The system is constructed with two parts: the transmitting unit measures the current, voltage, power and power factor through the compact new sensor PZEM-004T. The data sensed and processed by the microcontroller which displayed the $\mathrm{KWh}$ on $(2 * 16 \mathrm{LCD})$ display. This data also transmitted to the electrical power company unit via the global system for mobile communications (GSM) module (SIM900A) which is a dual band GSM/GPRS-general packet radio service modem. The receiving part is mainly dedicated for collecting the required consumed power data via the same (SIM900A) module and also can display it using (2*16 LCD) display. For the sake of saving these data, the receiver part uses SD ram for such purposes. With such proposed system the electrical power company can control and collect their fees monthly without loss and with minimum cost.
\end{abstract}

This is an open access article under the CC BY-SA license.

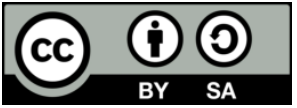

\section{Corresponding Author:}

Nadhir Ibrahim Abdulkhaleq

Department of Mobile Computing and Communications Engineering-College of Engineering

University of Information technology and Communications (UoITC)

Al Naqabat Str. Al Mansour, Baghdad, Iraq

Email: nadhir.abdulkhaleq@uoitc.edu.iq

\section{INTRODUCTION}

After 1990 and specially after the second gulf war, Iraq had witnessed many problems in the field of electrical power generation as well as distribution systems. Due to large damages that taken place in this field the Iraqis stated many projects to re-building their own power plants and depending on their resources. The problem of power demands began to be more serious after the events of 2003. The challenges for achieving these demands become more sever with the rabid increase of the population and random cities. According to last annual reports from the Ministry of Electricity in Iraq [1], [2], the total production of the electrical power that reported as a sold energy to the customers is about 39,593,993 MW. However, the Ministry of Electricity said [2] that $50 \%$ of such sold energy has been paid. This great loss of incomes is our motivation for constructing such cheap smart power meter aided with a global system for mobile communications (GSM) module to help collecting the energy fees automatically. The online resources of Arduino and its huge applications make it a favorite microcontroller for many projects [3]-[9]. The requirements for constructing 
smart cities impose new trends towards smart meters. Smart power meters are reliable, cheap and had the ability for design updating. In the last few years many papers had been published dealing with smart power meters. In [10]-[13], the energy demands from the consumers are monitored and controlled using smart power meter. A real time monitoring is achieved via an IoT technology and the whole implementation has been done using LabView. Afridi et al. [14], presented another way of controlling the power consumption by using a GSM based smart meter which is utilized for reducing the human faults that made an electricity lost. The smart meter provided an automatic reading for the electrical energy rather than the usual action done by the company employers. In [15]-[24], a forward metering information has been built in order to minimize the level of energy theft. The design also aided by a GSM utility for remote controlling the smart metering architecture.

Some other applications for smart energy meter have been presented in the project of Nartha et al. [25]. An energy consumption meter and cost evaluation system for the power required to charge a battery of an electrical vehicle has been proposed in this project. Also, both Bluetooth and GSM modules are used for the communication link between the meter and the customer. While in [26] the smart meter is suggested with a cost calculations algorithm to be used in the local emergency generators which are used to compensate the main electrical grid shortages. The design with its new calculation method made the cost depends on the time of actual working of the generator multiplied by an updated price for the delivered amperes. In this project we aim to solve more than one problem:

- $\quad$ First replacing the old electro-mechanical meters that are being used till nowadays in Iraq.

- Make the electricity supplying companies monitoring their meters in the customer's side without the need for a direct contact especially with the need of social distancing regime during COVID-19 circumstances.

- The customers also could track their energy consumption and in other words their cost have to be paid, which may establish an indirect way for saving more energy especially during summer times.

- By displaying the voltage, power and power factor, this project made the customer able of monitoring the quality of the delivered power. In Iraq many drops or spikes in the delivered power cost a lot of damages for the home devise, by such reading with our device the customer could have an early message to take an advanced shutdown to avoid damages.

- With an short message service (SMS) carrying the electricity bills to the customer made these bills saved in their phone and easy to get them back when needed.

This paper has been organized as shown in: the next section is used to describe the system model which is consists of two main parts, the transmitter section and the receiver one. Section 3 is utilized for presenting the experimental results of the meter. The conclusion has been listed in section 4 .

\section{THE SYSTEM MODEL CONSTRUCTIONS}

The project is configured into two main parts, the transmitter and the receiver. Figure 1 illustrates the scenario which interpreting the function of the device. There are two types of lines in the Figure 1. The dashed blue lines representing the request from the local electricity company or the owner of the meter (home) from the smart meter to send the reading for power consumption. While the solid red lines represent the respond from the smart meter to these requests. This will be achieved via the following parts of the project.

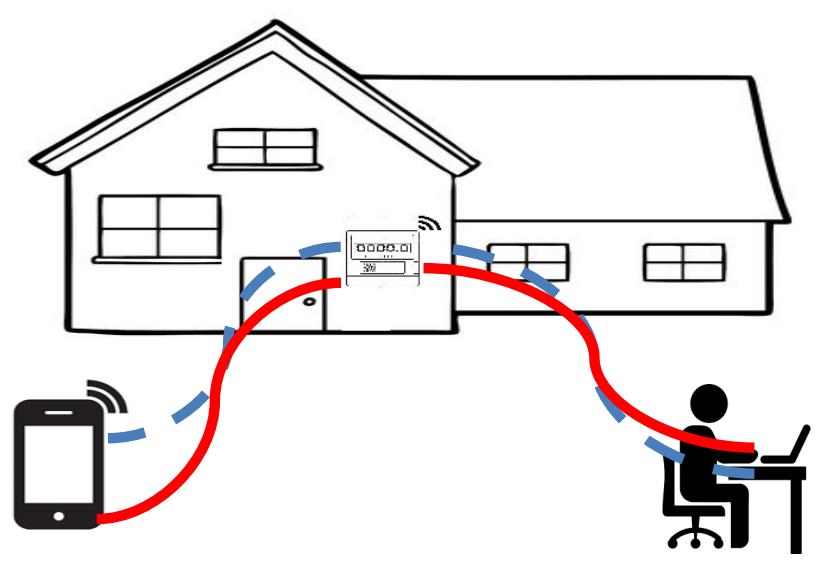

Figure 1. The scenario of information flow for the meter function 


\subsection{Transmitter part}

This section of the project is represented by the smart electrical power meter. The device can be mounted inside the control box for the electrical power of any place like a house, shop. Figure 2 shows the components of the smart meter. As shown in this figure the job of this device is to sense the delivered electrical power via the alternative current connected module PZEM-004T [27]. This module can serve to get the data related the applied voltage, the received current, active power and energy as well as the frequency of the $\mathrm{AC}$ incoming wave and the power factor of the delivered power to the customers. These group of measuring rates made this module suitable for the aim of our project. In Figure 3, the PZEM-004T module with its connection is illustrated. It has a measuring current range up to $100 \mathrm{~A}$ with starting sensed current at $0.02 \mathrm{~A}$ and this large scale of measurement is recorded with an accuracy of $0.5 \%$. The power factor which is one of the objectives of this project that aims to track its value, this module detects this value with an accuracy of $1 \%$. The active energy given by (1) is measured up to the value of $9999.99 \mathrm{kWh}$ and with accuracy of $0.5 \%$.

$$
\begin{aligned}
& E_{e f f}=P_{\text {eff }} \times \text { time } \\
& P_{\text {eff }}=I_{r m s} \times V_{r m s} \times \cos \phi
\end{aligned}
$$

where $\cos \phi$ represent the power factor.

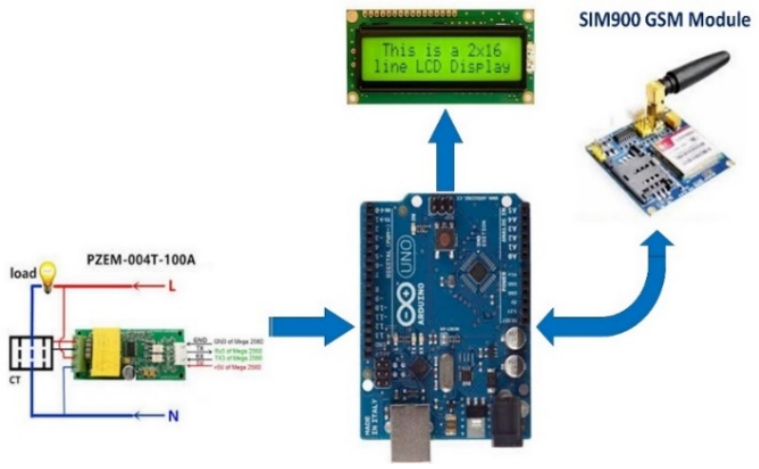

Figure 2. The components and data flow in the smart meter

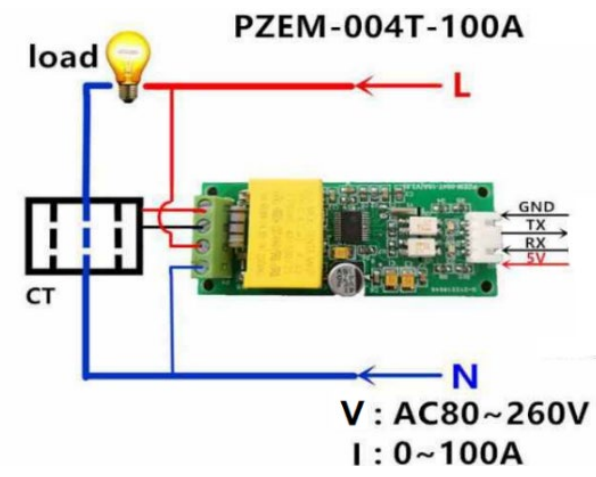

Figure 3. PZEM-004T module wiring diagram

The sensed readings of current and voltage are fed to the microcontroller. An Arduino Uno board based on the ATmega328P is used as the mother board of the transmitter part. The job of the microcontroller is to collect the available data on its inputs and processed them using a code that described by the flowchart shown in Figure 4. This flowchart indicates that when the data is available on the input pins the required effective energy is calculated and the waiting for the request of either the electricity company for the power consumption or from the house owner cell phone through the SMS services. The sending of measured data and receiving the SMS request will be achieved utilizing the GSM module shown in Figure 5 [26]. 


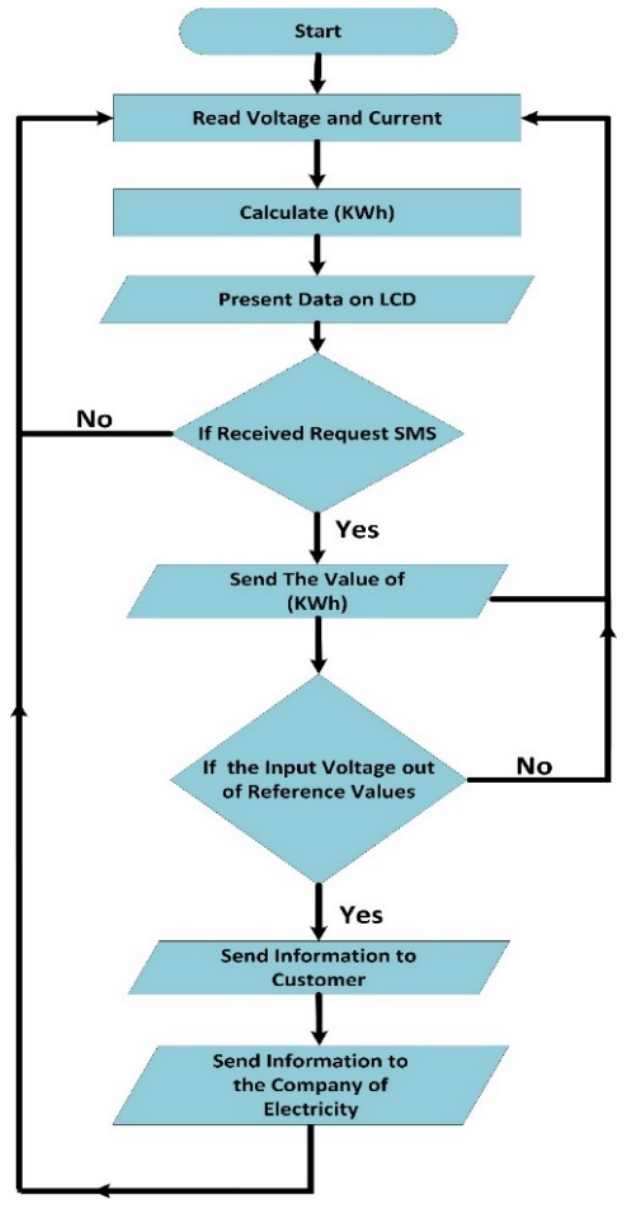

Figure 4. Flow chart of the data processing in the transmitter part
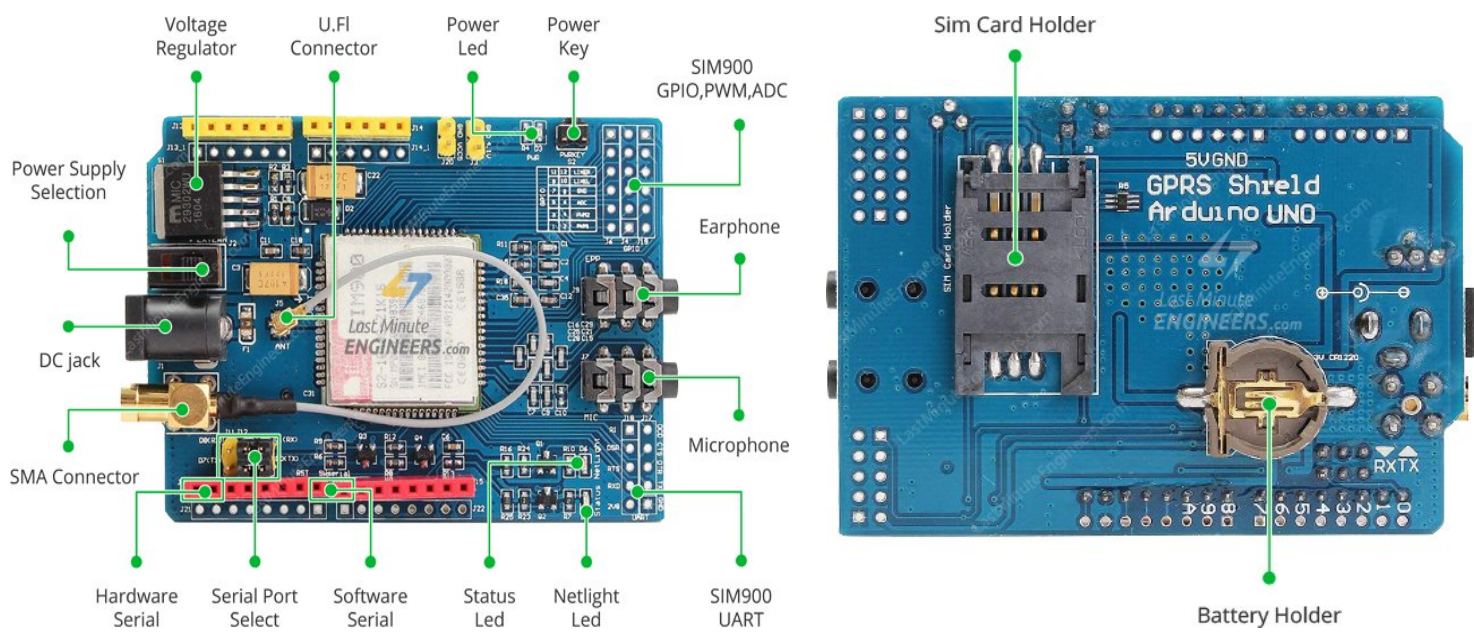

Figure 5. SIM900 GSM/GPRS module front and back panel

This module has the ability to do all the functions related to mobile phones. For instance, the flowchart shown in Figure 4 indicates that there are two main actions the transmitter can do. The first: responding to the SMS request sent by either the customer or the electricity company and the second: is to transmit a warning SMS for the customer when the supplied voltage get out of than the safe value that could make some damages for the appliances in the house for example. This option is so important for this smart meter which make him as a security device as well. 


\subsection{Receiver part}

The receiving unit of this smart meter is placed in the office of the electricity company of the city. Figure 6 is dedicated for illustration the construction and data flow of it. As shown in this figure, there are two main scenarios:

- The first one: is the case when the electricity company employer use the push-button to start the operation for sending a request to the dedicated house to send its reading for the energy consumption. The signal from the push-button is processed by the Arduino Uno and send a message as a request to the dedicated smart meter to send its data.

- The second option: this will be done by processing the data that has been received by the pair part of the SIM900 GSM module which has the function of transmitting/receiving the SMS data. All the data that contained in the messages are fed also to the Arduino Uno microcontroller and processed to get the required bill which can be displayed on the shown liquid crystal display (LCD) and stored in in the micro SD card module. All these actions are programmed and fed to the Arduino Uno and the flowchart for such actions is shown in Figure 7.

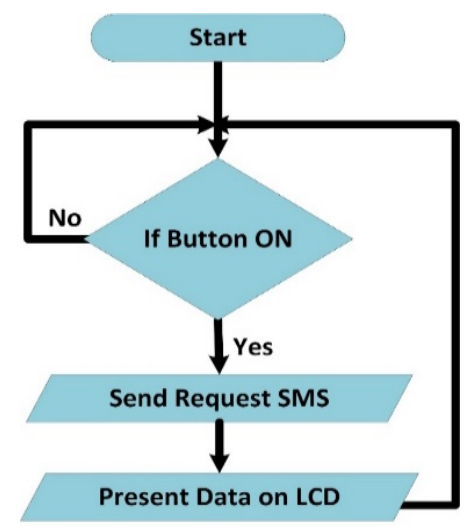

Figure 6. Components and data flow in the receiving part of smart meter

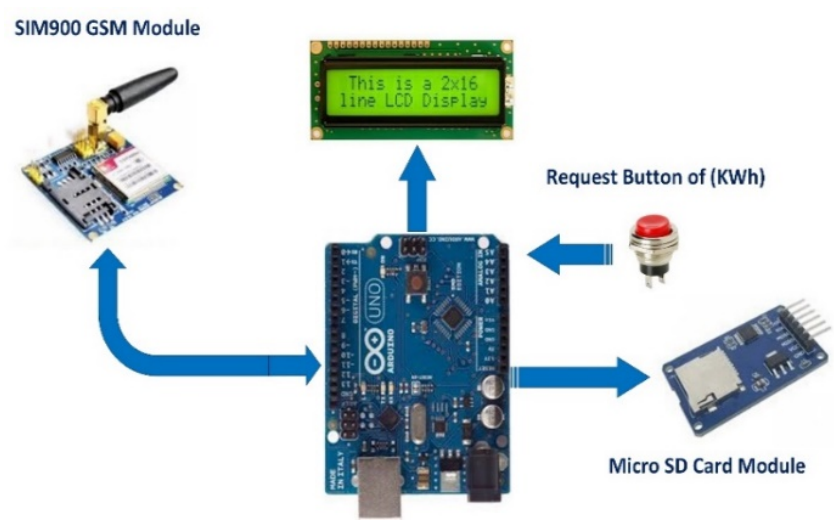

Figure 7. Flow chart for the function of the receiving part of the smart meter

\section{SMART METER IMPLIMENTATION AND TESTING}

The smart meter has equipped with two sim cards of one of the operating cell phone companies in Baghdad. The transmitter of the meter shown in Figure 8 has attached to a load and start testing the meter. It is shown that the meter keeps displaying the measured data represented by the current $(I=3.65 \mathrm{~A}$, $V=215$ and the $E \_$eff $=650 \mathrm{KWh}$ ). It is well known that this active energy been recorded for a period of time around one hour. The additional option of this meter is its monitoring of the supplied voltage whether it is in the safe range $200-250 \mathrm{~V}$, and with any extreme situation like dropping below $(V<190)$ and getting high $(V>260)$ a warning message will be send to both the customer and the supplying company. This action will save money and time for both the electricity provider and the customer to avoid damages for the appliance in home or the electricity installations., in case of unbalanced voltage supply. 
The other part of the meter which is used by the electricity supplying company is activated at certain time say each 30 days. The employer sends its request to get the reading of energy consumption by clicking the push button on the front panel of the device shown in Figure 9. The employer also could test the validity of the meter at any time by sending his request to get the reading of the meter. This option will minimize the need for the workers to go by themselves to explore the states of the meter, especially nowadays with the covid 19 pandemic.
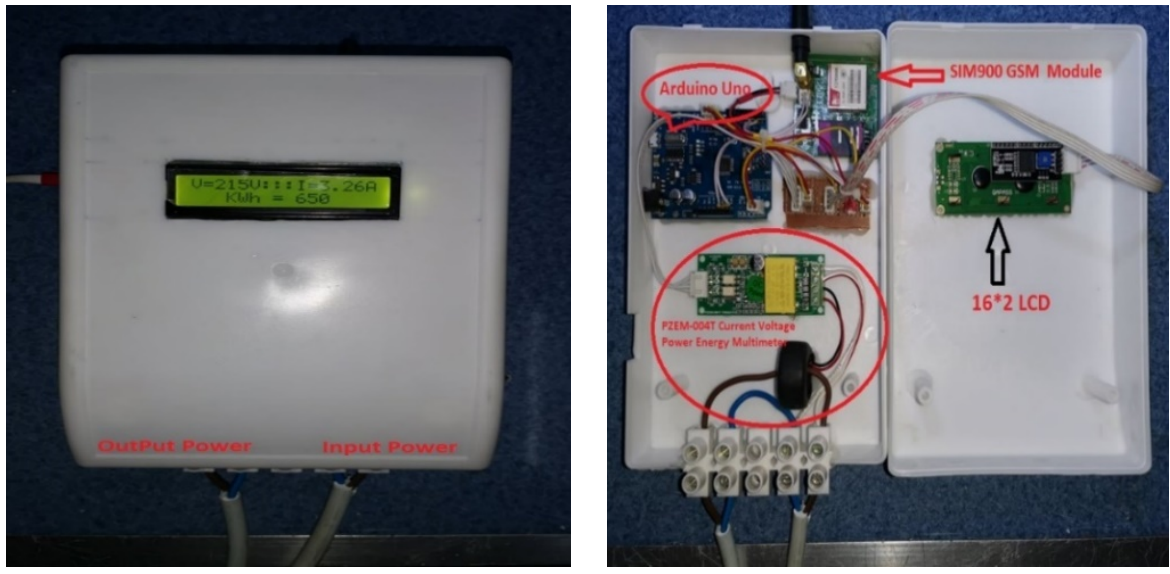

Figure 8. Implementation of the transmitting part of the smart meter
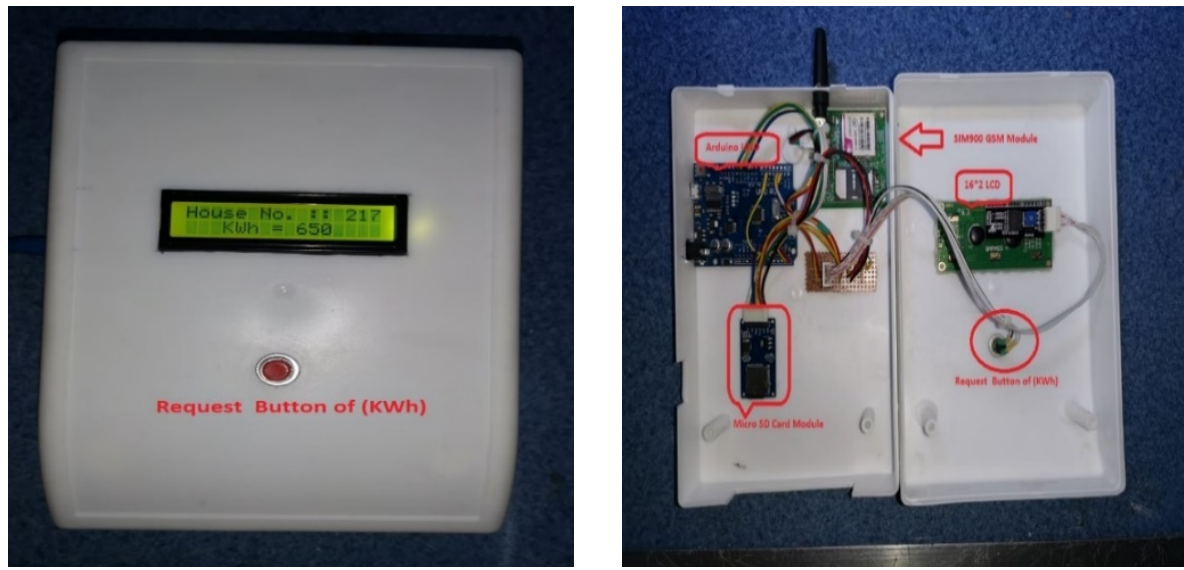

Figure 9. Implementation of the receiving part of the smart meter

\section{CONCLUSION}

This paper presents a GSM based smart meter using an Arduino Uno microcontroller. The two parts circuits of the smart meter complete the mission of each other to minimize the cost of monitoring the energy consumption in any place inside Baghdad city. The implementation of the transmitter part which use the Arduino and the PZEM-004T to sense the current and voltage and utilize the GSM module to send the energy consumption represented by the KWh reading. This message transmitted as a response for a request that send from the electricity local company employer which use the other part of the meter. The meter also offers an early warning message for the customer in case of unbalanced voltage supply to prevent any damages of his appliances. This meter could be used as a first step in transferring to smart devices in the electricity company in Baghdad city.

\section{REFERENCES}

[1] H. A. Kazem and M. T. Chaichan, "Status and future prospects of renewable energy in Iraq," Renewable and Sustainable Energy Reviews, vol. 16, no. 8, pp. 6007-6012, 2012, doi: 10.1016/j.rser.2012.03.058. 
[2] M. T. Chaichan and H. A. Kazem, "Solar Photovoltaic Technology Principles," in Generating Electricity Using Photovoltaic Solar Plants in Iraq, Cham: Springer International Publishing, 2018, pp. 47-82.

[3] N. A. J. Salih, I. J. Hasan, and N. I. Abdulkhaleq, "Design and implementation of a smart monitoring system for water quality of fish farms," Indonesian Journal of Electrical Engineering and Computer Science (IJEECS), vol. 14, no. 1, 2019, Art. no. 44, doi: 10.11591/ijeecs.v14.i1.pp44-50.

[4] A. Boniface, A. Y. Nasir, and A. M. Hassan, "Arduino based gas leakage and temperature monitoring and control system," International Journal of Informatics and Communication Technology (IJ-ICT), vol. 9, no. 3, pp. 171-178, 2020, doi: 10.11591/ijict.v9i3.pp171-178.

[5] I. J. Hasan, N. A. J. Salih, N. I. Abdulkhaleq, and M. J. Mnati, "An Android smart application for an Arduino based local meteorological data recording," IOP Conference Series: Materials Science and Engineering, vol. 518, no. 4, 2019, Art. no. 042014, doi: 10.1088/1757-899X/518/4/042014.

[6] Q. A. Azze and M. H. Ali, "Design and implement of pulse width modulation with low-cost hardware in the loop," International Journal of Power Electronics and Drive Systems (IJPEDS), vol. 11, no. 2, pp. 870-878, 2020, doi: 10.11591/ijpeds.v11.i2.pp870-878.

[7] A. H. M. Almawgani, "Smart monitoring system of Najran dam," International Journal of Electrical and Computer Engineering (IJECE), vol. 10, no. 4, pp. 3999-4007, 2020, doi: 10.11591/ijece.v10i4.pp3999-4007.

[8] N. I. Abdulkhaleq, I. J. Hasan, and N. A. J. Salih, "Investigating the resolution ability of the HC-SRO4 ultrasonic sensor," IOP Conference Series: Materials Science and Engineering, vol. 745, 2020, Art. no. 012043, doi: 10.1088/1757-899X/745/1/012043.

[9] I. J. Hasan, N. A. J. Salih, and N. I. Abdulkhaleq, "Three-phase photovoltaic grid inverter system design based on PIC24FJ256GB110 for distributed generation," International Journal of Power Electronics and Drive Systems (IJPEDS), vol. 10, no. 3, pp. 1215-1222, 2019, doi: 10.11591/ijpeds.v10.i3.pp1215-1222.

[10] S. G. Priyadharshini, C. Subramani, and J. P. Roselyn, "An IOT based smart metering development for energy management system," International Journal of Electrical and Computer Engineering (IJECE), vol. 9, no. 4, pp. 3041-3050, 2019, doi: 10.11591/ijece.v9i4.pp3041-3050.

[11] S. Jaiswal, M. S. Ballal, S. M. Kashif and R. Meena, "Demand side load management using GSM enabled smart energy meter," 2017 7th International Conference on Power Systems (ICPS), 2017, pp. 49-54, doi: 10.1109/ICPES.2017.8387267.

[12] I. J. Hasan and M. Shamshiri, "Reducing energy consumption and increasing comfort of users in intelligent buildings by employing learning automata," International Review of Electrical Engineering (IREE), 2019, vol. 14, no. 2, pp. 109-117, 2019, doi: 10.15866/iree.v14i2.15996.

[13] I. J. Hasan, M. R. Ab. Ghani, and C. K. Gan, "Optimum Distributed Generation allocation using PSO in order to reduce losses and voltage improvement," in 2014 IET Seminar Digest (CP659), 2014, pp. 29-35, doi: 10.1049/cp.2014.1476.

[14] M. Subashini, S. Das, S. Heble, U. Raj, and R. Karthik, "Internet of things based wireless plant sensor for smart farming," Indonesian Journal of Electrical Engineering and Computer Science (IJEECS), vol. 10, no. 2, pp. 456-468, 2018, doi: 10.11591/ijeecs.v10.i2.pp456-468.

[15] K. S. Kavithakumari, P. P. Paul and E. C. Amala Priya, "Advance metering infrastructure for smart grid using GSM," 2017 Third International Conference on Science Technology Engineering \& Management (ICONSTEM), 2017, pp. 619-622, doi: 10.1109/ICONSTEM.2017.8261396.

[16] N. Khan, Y. Naseer, I. Alam, T. Abbas and Y. Iqbal, "Wireless controlled smart digital energy meter and theft control using GSM with GUI," 2018 International Conference on Computing, Mathematics and Engineering Technologies (iCoMET), 2018, pp. 1-6, doi: 10.1109/ICOMET.2018.8346430.

[17] A. S. Metering, S. Visalatchi and K. K. Sandeep, "Smart energy metering and power theft control using arduino \& GSM," 2017 2nd International Conference for Convergence in Technology (I2CT), 2017, pp. 858-961, doi: 10.1109/I2CT.2017.8226251.

[18] M. M. Rahman, Noor-E-Jannat, M. O. Islam and M. S. Salakin, "Arduino and GSM based smart energy meter for advanced metering and billing system," 2015 International Conference on Electrical Engineering and Information Communication Technology (ICEEICT), 2015, pp. 1-6, doi: 10.1109/ICEEICT.2015.7307498.

[19] M. Prathik, K. Anitha and V. Anitha, "Smart Energy Meter Surveillance Using IoT," 2018 International Conference on Power, Energy, Control and Transmission Systems (ICPECTS), 2018, pp. 186-189, doi: 10.1109/ICPECTS.2018.8521650.

[20] S. W. Yen, S. Morris, M. A. G. Ezra, and T. J. Huat, "Effect of smart meter data collection frequency in an early detection of shorter-duration voltage anomalies in smart grids," International journal of electrical power \& energy systems, vol. 109, pp. 1-8, 2019, doi: 10.1016/j.ijepes.2019.01.039.

[21] A. Chaudhari and P. Mulay, "A bibliometric survey on incremental clustering algorithm forelectricity smart meter data analysis," Iran Journal of Computer Science, vol. 2, no. 4, pp. 197-206, 2019, doi: 10.1007/s42044-01900043-0.

[22] F. Al-Turjman and M. Abujubbeh, "IoT-enabled smart grid via SM: An overview," Future generations computer systems: FGCS, vol. 96, pp. 579-590, 2019, doi: 10.1016/j.future.2019.02.012.

[23] S. Sutil, F., A. Cano-Ortega, J. C. Hernandez, and C. Rus-Casas, "Development and calibration of an open source, low-cost power smart meter prototype for PV household-prosumers," Electronics, vol. 8, no. 8, 2019, Art. no. 878, doi: $0.3390 /$ electronics 8080878 .

[24] S. Zhang, T. Zheng. and B. Wang, "A privacy protection scheme for smart meter that can verify terminal's trustworthiness," International journal of electrical power \& energy systems (IJEPES), vol. 108, pp. 117-124, 2019, doi: 10.1016/j.ijepes.2019.01.010.

A global system for mobile communications-based electrical power consumption for ... (Ihsan Jabbar hasan) 
[25] I. M. A. Nrartha, A. B. Muljono, I. M. Ginarsa, S. M. Al Sasongko and I. B. F. Citarsa, "Smart Energy Meter for Electric Vehicle Based on Bluetooth and GSM Technology," 2018 International Conference on Smart Green Technology in Electrical and Information Systems (ICSGTEIS), 2018, pp. 7-12, doi: 10.1109/ICSGTEIS.2018.8709139.

[26] B. M. Waheib, I. J. Hasan, N. A. Jalil Salih, and N. I. Abdulkhaleq, "Design of smart power meter for local electrical power generators in Baghdad city," IOP Conference Series: Materials Science and Engineering, vol. 881, 2020, Art. no. 012105, doi: 10.1088/1757-899X/881/1/012105.

[27] M. J. Mnati, A. Hasan, A. H. Ali, D. V. Bozalakov, and A. Van den Bossche, "Design and implementation A smart monitoring and controlling system of three-phase photovoltaic inverter based on LoRa," IOP Conference Series: Materials Science and Engineering, vol. 518, 2019, Art. no. 042022, doi: 10.1088/1757-899X/518/4/042022.

\section{BIOGRAPHIES OF AUTHORS}
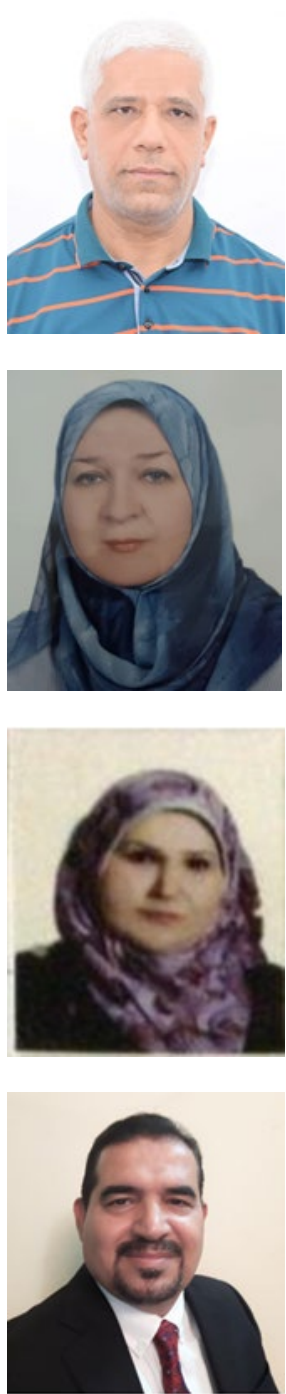

Ihsan Jabbar Hasan was born in Baghdad in1966. He received BSc in electrical engineering from Cairo, Egypt in 1990 and MSc in electrical power engineering from the Foundation of Technical Education-College of Electrical and Electronic Techniques, Baghdad, Iraq in 2007, the $\mathrm{PhD}$ degree from the Universiti Teknikal Malaysia Melaka (UTeM) in 2015. He currently works as an Asst. Prof. in the Middle Technical College, Baghdad, Iraq. He had published several papers in the field of power distribution network, demand response techniques, power system planning, network planning and optimization.

Bushra Mahmoud Wahieb is a member of the department of Electronic Techniques in the Institute of Technology at The Middle Technical University in Iraq. She received her BSc in Control and Systems Engineering from University of Technology, Baghdad, Iraq in 1986, she received her MSc in Control and Instruments engineering from the Control and Systems department at The University of Technology Baghdad Iraq in 1993.Her interests are control systems optimization and computer aided designs.

Nahla Abdul Jalil Salih is a member of the department of Electronic Techniques in the Institute of Technology in Middle Technical University in Iraq. she received his BSc in control and systems Engineering from university of technology, Baghdad, Iraq in 1992, her interests are control and systems, fractal coding technique, digital image coding.

Nadhir Ibrahim Abdulkhaleq had his BSC in Electrical Engineering from Cairo-Egypt in 1990 and MSc. in Radar and Communication from the Technology University in Baghdad-Iraq in 1995, the PhD in Electronic and Communication Engineering from Cankaya University in Turkey in 2017. He currently works as an Asst. Prof. in Department of Mobile Computing and Communications Engineering-College of Engineering University of Information technology \& Communications (UoITC). He had published several papers in the field of coding theory and wireless sensor networks. 